\title{
Foreign direct investment, economic freedom and economic growth: international evidence
}

\begin{abstract}
In this paper, we investigate the systemic link between economic freedom, foreign direct investment (FDI) and economic growth in a panel of 85 countries. Our empirical results, based on the generalized method-of-moment system estimator, reveal that FDI by itself has no direct (positive) effect on output growth. Instead, the effect of FDI is contingent on the level of economic freedom in the host countries. This means the countries promote greater freedom of economic activities gain significantly from the presence of multinational corporations (MNCs).
\end{abstract}

Keyword: Foreign direct investment; Economic freedom; Economic growth; Absorptive capacity; Generalized method-of-moments; R\&D spillovers 